\title{
On Private Peering Agreements between Content and Access Providers: A Contractual Equilibrium Analysis
}

\author{
Xin Wang \\ National University of Singapore \\ xin.wang@comp.nus.edu.sg
}

\author{
Richard T. B. Ma \\ National University of Singapore \\ tbma@comp.nus.edu.sg
}

\begin{abstract}
Driven by the rapid growth of content traffic and the demand for service quality, Internet content providers (CPs) have started to bypass transit providers and connect with access providers directly via private peering agreements. This peering relationship often raises disputes, e.g., Netflix vs. Comcast, and is not well understood. In this paper, we build a peering contract model and propose the concept of contractual equilibrium, based on which we study the formation and evolution of peering contracts. By using market data, we emulate the strategic peering behavior of providers and shed light on the understanding of private peering agreements.

We reveal that the superiority and market dominance of providers primarily determine their peering strategies. We show that 1) superior providers tend to engage in peering more aggressively, and 2) non-dominant CPs' optimal peering strategies are negatively correlated due to market cannibalism, while the dominant $\mathrm{CP}$ often behaves oppositely. Our findings help explain phenomena such as why Netflix and Comcast signed the first peering contract, and reason whether private peering contracts will strengthen in future.
\end{abstract}

\section{CCS CONCEPTS}

- Networks $\rightarrow$ Network economics; Network performance modeling; Public Internet.

\section{KEYWORDS}

Internet; private peering; superiority; market dominance

\section{ACM Reference Format:}

Xin Wang and Richard T. B. Ma. 2021. On Private Peering Agreements between Content and Access Providers: A Contractual Equilibrium Analysis. In Abstract Proceedings of the 2021 ACM SIGMETRICS / International Conference on Measurement and Modeling of Computer Systems (SIGMETRICS '21 Abstracts), fune 14-18, 2021, Virtual Event, China. ACM, New York, NY, USA, 2 pages. https://doi.org/10.1145/3410220.3456277

\section{BACKGROUND AND PROBLEM}

Today's Internet is dominated by content traffic, especially video streaming. According to Sandvine 2018 Internet Phenomena Report [8], video is almost $58 \%$ of the total downstream Internet traffic, while Netflix solely contributes $15 \%$ of the downstream traffic across the entire Internet. To accommodate the increasing traffic demand

Permission to make digital or hard copies of part or all of this work for personal or classroom use is granted without fee provided that copies are not made or distributed for profit or commercial advantage and that copies bear this notice and the full citation on the first page. Copyrights for third-party components of this work must be honored For all other uses, contact the owner/author(s).

SIGMETRICS '21 Abstracts, fune 14-18, 2021, Virtual Event, China

(c) 2021 Copyright held by the owner/author(s).

ACM ISBN 978-1-4503-8072-0/21/06.

https://doi.org/10.1145/3410220.3456277 from users, large content providers (CPs) have been deploying widearea infrastructures so as to bring content closer to users and bypass transit providers on many paths [3]. For example, Netflix uses thirdparty content delivery networks, e.g., Akamai and Limelight, and builds its own [6]. This causes the flattening phenomenon [1,3] of the Internet topology, which transitioned from a transit hierarchy to a peering mesh.

However, regardless how flat the Internet could be, end-users still rely on the last-mile access providers (APs) for accessing the Internet. Thus, the limited capacity of APs may constrain users' download speed due to network congestion. For example, the average throughput of Netflix users behind Comcast, the largest U.S. broadband provider, degraded 25\% from over 2 Mbps in Oct 2013 to $1.5 \mathrm{Mbps}$ in Jan 2014 [7]. Only after Netflix purchased a direct connection from Comcast to its network via a private peering agreement in Feb 2014 [10], did the average user throughput rebounded almost doubly. Due to similar reasons, Netflix also signed another peering contract with Verizon two months later [4].

As a content service market, the entire Internet can be regarded as a two-sided platform, where CPs and APs may establish private peering agreements that affect the performance of content applications. Although from a service perspective, this peering relationship seems to be a collaborative effort between CPs and APs to improve service quality, the actual implementation is driven by the autonomous objectives and decisions of the contracting entities. In contrast to the traditional customer-provider relationship under which APs pay upstream entities transit fees, this type of peering often involves an AP imposing termination fees on a counterparty that specializes in content distribution and therefore, often causes peering disputes, e.g., Netflix-Comcast and Netflix-Verizon [5], in the bargaining process of contract negotiation. In the Netflix-Comcast dispute, for example, Netflix claimed that congestion was made intentionally by Comcast to force it to pay for direct connectivity; while Comcast claimed that Netflix was sending more traffic to transit providers than what they could accommodate and caused congestion. These peering disputes also raise policy concerns such as net neutrality [9], and therefore, the U.S. Federal Communication Commission (FCC) has requested the peering agreements Netflix signed with Comcast and Verizon [5] for investigations.

Nevertheless, private peering is not well understood and has not been explored much in the research community, partially due to the lack of public data sources of peering agreements, which are often confidential business contracts. The difficulty also lies in the fact that any CP's peering decision is driven by the competition in the content market, as well as the bilateral bargaining with an AP, during which financial transfers are involved and potential disputes could happen. Ultimately, any bilateral contract depends on not 
only the two trading parties but also all other possible contracts engaged by other pairs of providers in the entire service market.

In this paper, we build an analytical peering contract model and propose the concept of contractual equilibrium, based on which we study the formation and evolution of peering contracts. In particular, we try to answer the questions: What kind of CP-AP pairs has strong incentives to sign the first peering contract? What is the best-response strategy of a peering pair if others sign peering contracts? How does a contractual equilibrium look like? How should a $\mathrm{CP}$ adapt its contracts with varying characteristics of itself and others? How does the equilibrium evolve when conditions of market environment change?

\section{CONTRACT MODEL}

We consider an Internet content market consisting of a set of CPs and APs which compete with each other for end-users. To provide content to users, CPs need to deliver content data via APs that users subscribe to. CPs and APs may wish to establish private peering through which users can obtain better service quality. We denote the set of CP-AP pairs that could potentially establish private peering and jointly serve end-users by $\mathcal{L}$. As a key to understanding the private peering between CPs and APs lies in the contracts they sign, we model the contract terms of a CP-AP pair $l \in \mathcal{L}$ by a tuple $\left(\phi_{l}, \psi_{l}\right)$ of contractual level and monetary transfer. The level $\phi_{l}$ models the amount of resource the AP deploys under the contract and reflects the data delivery quality provided by the AP. The transfer $\psi_{l}$ denotes the corresponding contractual payment from the CP to the AP. We define $\phi$ and $\psi$ to be the vectors of all contractual levels and transfers. We denote the entire contract profile by $(\phi, \psi)$ and the profile except pair l's contract by $\left(\phi_{-l}, \psi_{-l}\right)$.

Because any contractual level $\phi_{l}$ affects the service quality for users who choose the pair $l$ of providers, it influences the choices of users among alternative providers and therefore affects the market share and profits of providers. We defined the profits of any $\mathrm{CP}$ $m$ and AP $n$ by $P_{m}(\phi, \psi) \triangleq U_{m}(\phi)-\sum_{k \in \mathcal{L}^{m}} \psi_{k}$ and $Q_{n}(\boldsymbol{\phi}, \psi) \triangleq$ $\sum_{k \in \mathcal{L}_{n}} \psi_{k}-V_{n}(\phi)$, where $\mathcal{L}^{m}$ and $\mathcal{L}_{n}$ define the set of CP-AP pairs involving CP $m$ and AP $n$, respectively, and $U_{m}(\phi)$ and $V_{n}(\phi)$ denote the CP's revenue and AP's cost, respectively. Here, the profit of a $\mathrm{CP}$ is defined as its revenue (from users or advertisers) minus the payments to APs, while the profit of an AP is defined as its received payments from $\mathrm{CPs}$ minus its cost for fulfilling the peering.

To understand what peering contracts would be signed between CPs and APs, we define an optimal contract that is ideally desirable for a pair of CP and AP to reach. A contract $\left(\phi_{l}, \psi_{l}\right)$ of any CP-AP pair $l$ is optimal if the contractual level $\phi_{l}$ maximizes the aggregate profit of the $\mathrm{CP}$ and $\mathrm{AP}$ and the contractual payment $\psi_{l}$ equalizes the profit gain, i.e., the difference in profit derived from signing a contract, for both providers. Based on the characterization of optimal contract, we define contractual equilibrium that specifies what contract profile will be formed between all CP-AP pairs.

Definition 2.1 (Contractual Equilibrium). A contract profile $(\phi, \psi)$ is a contractual equilibrium if for any CP-AP pair $l \in \mathcal{L},\left(\phi_{l}, \psi_{l}\right)$ is an optimal contract given the contracts $\left(\phi_{-l}, \psi_{-l}\right)$ of others.

Similar to Nash equilibrium, a contractual equilibrium is defined for any bilateral contract $\left(\phi_{l}, \psi_{l}\right)$, which specifies the conditions under which the parties $l=(m, n)$ reach to their optimal contract and thus will not have incentives to "unilaterally" change the contract. This ensures the stability of contracts specified under equilibrium.

\section{MAIN RESULTS}

By using market data as inputs to the contract model, we emulate the strategic peering behavior of providers. Combining with theoretical analysis, we reveal that the superiority and market dominance of providers play key roles in determining their optimal peering strategies. The former is defined by two intrinsic properties of providers, while the latter is determined by whether a $\mathrm{CP}$ obtains more than half of the entire user market. In particular, our main findings are as follows: 1) A CP-AP pair is more likely to sign the first peering contract if they are superior to their competitors. In general, superior providers also tend to maintain contracts at high levels and obtain high market shares; 2) In response to enhanced peering relationship between other providers, non-dominant $\mathrm{CPs}$ will weaken their peering contracts due to market cannibalism. However, a dominant $\mathrm{CP}$ will behave oppositely; 3) As a CP becomes superior and dominant, most peering contracts, even its own, will weaken; 4) As the market penetration and quality requirements increase for the Internet content, non-dominant CPs will strengthen their peering contracts, while a $\mathrm{CP}$ will behave oppositely after it dominates the market. We believe that the findings shed light upon the understanding of private peering agreements between content and access providers.

\section{ACKNOWLEDGEMENTS}

We would like to thank the anonymous reviewers and our shepherd Prof. Adam Wierman from the SIGMETRICS program committee for the insightful comments and suggestions. This work was supported in part by the National Research Foundation, Prime Ministers Office, Singapore under its Corporate Laboratory@ University Scheme, National University of Singapore, and Singapore Telecommunications Ltd.

\section{REFERENCES}

[1] Amogh Dhamdhere and Constantine Dovrolis. 2010. The Internet is flat: Modeling the transition from a transit hierarchy to a peering mesh. In Proceedings of 6 th ACM Conference on Emerging network experiment and technology. Article No. 21.

[2] Francisco Facchinei and Jong-Shi Pang. 2007. Finite-dimensional variational inequalities and complementarity problems. Springer Science \& Business Media.

[3] Phillipa Gill, Martin Arlitt, Zongpeng Li, and Anirban Mahanti. 2008. The flattening Internet topology: natural evolution, unsightly barnacles or contrived collapse?. In Proceedings of the 9th International Conference on Passive and Active Network Measurement. 1-10.

[4] Sam Gustin. 2014. Netflix Pays Verizon in Streaming Deal, Following Comcast Pact. In Time (28 Apr). http://time.com/80192/netflix-verizon-paid-peeringagreement/.

[5] Victor Luckerson. 2014. Netflix's Disputes With Verizon, Comcast Under Investigation. In Time (13 fun). https://time.com/2871498/fcc-investigates-netflixverizon-comcast/.

[6] Netflix.com. 2014. Open Connect. Retrieved July 10, 2019, https://openconnect. netflix.com/en/.

[7] Netflix.com. 2015. Netflix ISP Speed Index. Retrieved July 10, 2019, https:// ispspeedindex.netflix.com/country/us/.

[8] Sandvine. 2018. Global Internet Phenomena Report. Retrieved July 10, 2019, https://www.sandvine.com/hubfs/downloads/phenomena/2018-phenomenareport.pdf.

[9] Tim Wu. 2003. Network Neutrality, Broadband Discrimination. Journal of Telecommunications and High Technology Law 2 (2003), 141-179.

[10] Edward Wyatt and Noam Cohen. 2014. Comcast and Netflix Reach Deal on Service. In The New York Times (23 Feb). https://www.nytimes.com/2014/02/24/ business/media/comcast-and-netflix-reach-a-streaming-agreement.html. 